\title{
La Mendicidad de los Niños, Niñas y Adolescentes en el Perú
}

\author{
Children and adolescent beggars in Perú
}

\author{
Luis Enrique Pazos Maldonado ${ }^{(*)}$
}

\section{Resumen}

Este artículo busca, inicialmente, dar a conocer algunos conceptos de mendicidad ya desarrollados por juristas y estudiosos de esta conducta, tanto desde la perspectiva jurídica como social y psicológica.

Posteriormente, mediante una sinopsis se muestra la realidad y situación por la que nuestro país vive y enfrenta esta triste realidad; dictando normas y acatando disposiciones supranacionales, desarrollando programas que lamentablemente no logran disminuir o erradicar esta actividad nociva que frustra el desarrollo de nuestros niños, niñas y adolescentes.

Seguidamente, hago una referencia sobre la noción de infancia y su desarrollo en el tiempo y en la sociedad, lográndose, en un período corto, muchos derechos en su favor.

Finalmente, desde mi punto de vista expreso algunas imperfecciones tanto de la ley como de su reglamento; seguidamente, cito algunas de las disposiciones más importantes y vigentes para nuestro país, así como también presento dos flujogramas, uno de coordinación del MIMP con otras Instituciones y el segundo referido al procedimiento determinado por el D.S. 001-2005-MIMDES.

\section{Palabras Clave}

Mendicidad, Noción de Infancia, Ley 28190 y su Reglamento, Normatividad vigente.

\section{Abstract}

This article aims at first at presenting some of the concepts on begging that have already been developed by scholars and jurists, considering legal, social, and psychological perspectives.

\footnotetext{
${ }^{*}$ Abogado. Bachiller en Derecho y Abogado por la Universidad de San Martín de Porres. Con estudios concluidos de Maestría en Derecho Civil. Experiencia en el ejercicio de la profesión: Ex-Magistrado (s) Especializado de Familia en lo Civil de la Corte Superior de Lima.
}

Fecha de recepción: 20/09/2014

Fecha de aceptación: 23/10/2014 
Subsequently, the author provides a synopsis of reality and the current situation of how our country addresses and faces this sad reality; passing rules and following supranational provisions, developing programs that unfortunately fail to reduce or eliminate this harmful activity that thwarts the development of our children and adolescents.

Then the author refers to the notion of infancy and child development over time and within their community, and how they have achieved, in a short period of time, many rights in their favor.

Finally, the author describes, what in his view, are some imperfections of both the law and its regulations; then he quotes some of the most important provisions in force for our country while including two flowcharts, one on MIMP coordination with other agencies and the second one describing the specif procedure set out under S.D. 0012005-MIMDES.

\section{Key words}

Begging, Notion of Infancy, Act 28190 and its Regulations, Current regulations.

\section{Introducción}

A diario, por diferentes medios de comunicación, recibimos noticias sobre niños, niñas y adolescentes en estado de mendicidad; leer, escuchar, ver la cruda realidad a la que se encuentran sometidos por los maltratos, violaciones e incluso muertes por no entregar el dinero obtenido en el día.

La marginación de este grupo etario, lo convierte en presa fácil para ser captado por la delincuencia y personas de mal vivir, incursionándolos en el mundo de las drogas, prostitución, formando a otros como sicarios, entre otros delitos más, instruidos, aconsejados, incluso, por sus propios padres.

La mayoría de ellos provienen de familias excluidas socialmente, disfuncionales, otras que migran del campo a la ciudad en busca de un mejor futuro sin lograrlo.

La noción de infancia, a través del tiempo, se ha transformado como consecuencia de los cambios y evolución de la sociedad, tanto por la cultura, la ciencia, comunicación y tecnología, agregando, hoy, la globalización a la que estamos sujetos por la modernidad. 


\section{Conceptos de Mendicidad}

Antes de entrar en el tema propio de la mendicidad, presento los siguientes conceptos para ubicarnos en su contexto real.

A) La Mendicidad, en el Diccionario Enciclopédico de Derecho Usual de Guillermo Cabanellas, ${ }^{1}$ está definida como:

"Estado, condición y vida del Mendigo; del que vive de la limosna..., Desde el enfoque social: "En cualquiera de sus enfoque, la mendicidad constituye un mal social. Revela el desequilibrio entre las clases sociales, cuando algunos de los individuos carecen de medios o instituciones para remediar sus desgracias..., Para el Gobierno de un pueblo constituye permanente acusación de que no sabe promover el trabajo o los establecimientos para socorro o asistencia para menesterosos. La mendicidad humilla al que pide la limosna."

El mendigo está definido como:

"En la expresión del pauperismo o de la vagancia profesional, el dedicado habitualmente a la mendicidad."

B) La Ley $28190^{2}$, de fecha 16-03-04, prescribe que la mendicidad debe entenderse como:

"...la práctica que consiste en obtener dinero y recursos materiales a través de la caridad pública. En el caso de los niños, niñas y adolescentes esta práctica causa daños irreparables en su identidad e integridad, afecta sus derechos fundamentales y los coloca en situación de vulnerabilidad y riesgo."

C) El Reglamento de la ley $N^{\circ} 28190$, "Ley que protege a los menores de edad de la mendicidad", dado el 16-03-04, aprobado mediante D.S. $\mathrm{N}^{\circ}$ 001-05-MIMDES, ${ }^{3}$ define en el $2^{\circ}$ el concepto de mendicidad de los niños, niñas o adolescentes como:

"Aquella actividad permanente o eventual de solicitar dinero o recursos materiales, para su subsistencia u otros fines, en su beneficio, el de sus familiares o de terceros a

1 Cabanellas, Guillermo. (1979) Diccionario Enciclopédico de Derecho Usual; 12a . Edición, Tomo IV, pp. 382-383; 1979; Editorial Eliasta S.R.L. Buenos Aires-República, Argentina.

2 Publicada en el Diario Oficial "El Peruano" el 18-03-04, p. 264812.

3 Publicado en el Diario Oficial "El Peruano" el 19-01-05, p. 284847 a la 284851. 
través de la caridad pública, bien sea motivado por su situación de necesidad o de abandono o porque es ocasionado, inducido o utilizado para ello por sus padres, tutores, curadores o terceros responsables de su cuidado y protección, sin obligación de brindar contraprestación alguna."

\section{Mendicidad}

Si bien estas definiciones, nos ilustran sobre cómo es que debemos entender a la mendicidad, también lo es que nos permite visualizar la existencia de una triste y cruda realidad cotidiana por la exclusión social a la que se encuentra sujeta una parte de la infancia, no solo nacional, sino también mundial. Es de observar que su origen es consecuencia de políticas sociales injustas y discriminatorias e indolencia de un sector de la clase política, así como de otros grupos del sector industrial privado, que no contribuyen en forma efectiva para lograr su erradicación.

La historia y literatura universal de siglos pasados, nos enseña que la mendicidad ha estado presente en diferentes estadios de la humanidad.

Nuestro país no ha sido ni es ajeno a esa realidad, pues, a través de los años, vemos por nuestras calles, restaurantes, iglesias, puerta de los cines y ahora en el transporte público, ya no con asombro y con voluntad de ayuda o colaboración, sino con normalidad, naturalidad e indiferencia de la ciudadanía y de las propias autoridades, la presencia de muchos niños, niñas y adolescentes dedicados a esta cruel actividad a través de la venta de golosinas y otros objetos, cantando, haciendo malabares a diferentes horas del día o de la noche, bajo el pretexto de que están laborando, y lo que realmente están practicando es la mendicidad; algunos para apoyar a sus familias como si fueran unidades de producción y otros manejados por mafias, familiares o terceros que les exigen, con intimidación, a realizar dicha actividad, transgrediendo sus derechos fundamentales.

Coexiste, en el medio, otro grupo de personas inescrupulosas que, con el objeto, también, de obtener una dadiva o limosna de los transeúntes, a través de la compasión y miseria humana, manipulando emocionalmente a los transeúntes, exponen a sus niños, niñas y/o adolescentes con múltiples enfermedades, para que en su estado de incapacidad, sin importarles el agravamiento del estado de su salud, esto, sin considerar la hora o estado climático en que los exhiben, con el móvil de obtener dinero para sobrevivir en unos casos y en otros solo para lucrar a costa de ellos. 
También existe otra partida de pillos dedicados (dentro de las mafias o no) a embarazar a las niñas y adolescentes para enviarlas a las calles $y$, en su estado de gestación y/o con sus bebes en brazos, dándoles de lactar o no, contando su desgracia, den lastima, compasión y conseguir, a través de la misericordia ajena, limosnas bajo la apariencia de estado de necesidad, presentándolas con bolsas de caramelos, frunas, etc., para argumentar al colectivo civil o ante alguna intervención de las autoridades, que están trabajando. Un número significativo corresponde a niñas o adolescentes del cordón marginal de las ciudades y otras son traídas de zonas Andinas o de Selva bajo engaños de estudio o trabajo.

La exclusión social y desprotección en la que se encuentra sometido este grupo de temprana edad, no permite que desarrollen sus capacidades en el campo estudiantil, cultural y social.

¿Dónde están las autoridades del Ministerio Público, Policía Nacional, Gobiernos Regionales y Locales, y del Ministerio de Salud para salvaguardar la integridad y salud de estos niños, niñas y adolescentes que, conforme a nuestra Constitución, leyes y Convenios Internacionales están obligados a actuar para acogerlos y protegerlos.?

Entre otros efectos, obviamente negativos, que acarrea la mendicidad están los que lesionan la dignidad de la persona, dañan la integridad e identidad de los niños, niñas y adolescentes.

Es de prestar atención que la edad de la mayoría de los que conforma este grupo etario, utilizados para la mendicidad, fluctúa desde recién nacidos hasta los 17 años de edad.

Por eso, cabe preguntarnos, en qué lugar de las políticas públicas se ubica el tan predicado y también discutido interés superior del niño o favor minoris cuando nuestro país no da cumplimiento pleno al principio $2^{\circ}$ de la Declaración de los Derechos de los Niños y Adolescentes (aprobada por la Asamblea General de la ONU el 20 de noviembre de 1959) que a la letra dice:

"El niño gozará de una protección especial y dispondrá de oportunidades y servicios, dispensado todo ello por la ley y por otros medios, para que pueda desarrollarse fisica, mental, moral, espiritual y socialmente en forma saludable y normal, así como en condiciones de libertad y dignidad. Al promulgar leyes con este fin, la consideración fundamental a que se atenderá seráel interés superior del niño." 
$Y$ de igual manera, tampoco al artículo $3^{\circ}$ inciso $1^{\circ}$ de la Convención sobre los Derechos del Niño (entró en vigor en nuestro país el 04 de octubre de 1990) que establece:

"En todas las medidas concernientes a los niños, que tomen las instituciones públicas o privadas de bienestar social, los tribunales, las autoridades administrativas o los órganos legislativos, una consideración primordial a que se atenderá será el interés superior del niño".

Si bien es cierto que el Estado a través del Ministerio de la Mujer, denominado primero PROMUDEH, después MIMDES hoy MIMP, ha desarrollado un sin número de programas pensando en el interés superior del niño y en sus familias, mediante los cuales busca arrancarlos de la mendicidad, estos no son exitosos por múltiples factores, por citar: ineficacia en el cumplimiento de las normas, infraestructura, presupuesto, desorden directivo e informativo, etc.

Es de advertir, de las noticias propaladas día a día por los diferentes medios noticiosos, que no se logra acabar con este flagelo social. Se colige de esta situación, que los programas no cuentan una logística acorde a la magnitud del problema.

El Congreso de la República, ante la inseguridad social generada por la mendicidad, dicta la Ley $N^{\circ} 28190$, "Ley que protege a los Menores de Edad de la Mendicidad", (publicada en el diario oficial "El Peruano el 18-03-2004) y su Reglamento, sancionado por D.S. 001-2005-MIMDES, publicado en el diario oficial "El Peruano el 19-01-2005 (ver anexo 2) con el fin de corregir tan magna dificultad social que aqueja a la niñez y familias de nuestro país. Estos dispositivos legales, por sí solos, no han logrado remediar dicha realidad, al no contar, reitero, con un presupuesto y logística acorde a la dimensión del problema.

Sin perjuicio de las disposiciones contenidas en la Ley $\mathrm{N}^{\circ} 28190$, es de expresar que contiene algunas imperfecciones de redacción que no permiten una mejor comprensión y a plicación de la norma, por citar:

Artículo $2^{\circ}$, el texto de la sumilla, que es parte integrante del artículo, dice: "ámbito de aplicación", la cual, no guarda correspondencia con su contenido. La palabra "ámbito", en el Diccionario Enciclopédico de Derecho Usual de Guillermo Cabanellas está definida como: 
"Término amplísimo pera referirse a situaciones o lugares, por expresar tanto el contorno o perímetro de un espacio como lo comprendido dentro de determinados límites. Cabe aplicarlo desde un minifundio a todo un continente..."

El vocablo "aplicación," conforme al Breve Diccionario Etimológico de la Lengua Española ${ }^{4}$ tiene como significado:

"acción de aplicar, de poner algo en contacto o adaptar; asiduidad, diligencia, esfuerzo..."

En el Diccionario Enciclopédico de Derecho Usual de Guillermo Cabanellas ${ }^{\mathbf{5}}$ en su primera definición tiene como significado:

"Acción yefecto de aplicar o aplicarse..."

También como:

"Aplicación de las Leyes. Efectiva vigencia de las mismas por espontaneo cumplimiento o por imposición de las autoridades administrativas ojudiciales// En el pragmatismo jurídico, preceptos genéricos para que rijan en realidad las leyes y otras disposiciones generales; como reglamentos, ordenanzas, decretos, órdenes y bandos..."

El texto del citado artículo empieza mencionando: "Entiéndase por mendicidad la práctica que consiste en obtener dinero y recursos materiales a través de la caridad pública. En el caso de los niños y adolescentes esta práctica causa daños irreparables en su identidad e integridad, afecta sus derechos fundamentales y los coloca en situación de vulnerabilidad y riesgo."

Si bien el vocablo "entiéndase" no está registrado en el Diccionario de la Real Academia Español ${ }^{6}$, su forma con una escritura más cercana es "entender" cuyo significado está referido: "a tener idea clara de las cosas" y

\footnotetext{
4 Diccionario de la Real Academia Española DRAE (2001). Versión Electrónica, 220 edición, Disponible en: http:/ /lema.rae.es/drae/?val=aplicaci\% C3\%B3n Consultado el 22-09-2014.

5 Cabanellas, Guillermo. (1979) Diccionario Enciclopédico de Derecho Ustal; 12a. Edición, Tomo IV, pp. 332,333; Editorial Eliasta S.R.L. Buenos Aires-República, Argentina.

6 Diccionario de la Real Academia Española DRAE (2001). Versión Electrónica, 220 edición, 2001 Disponible en: http://lema.rae.es/drae/?val=entiendase, 01-09-14.
} 
conforme al Breve Diccionario Etimológico de la Lengua Española ${ }^{7}$ tiene como significado: "comprender, percibir el sentido, tener una idea clara (de)..."

Su inserción al inicio del texto del artículo revela, claramente, que está precisando conceptualmente la definición de mendicidad, más no está determinado el ámbito de su aplicación (competencia), generando confusión al momento de actuarla; pero, aun cuando no la fija, sabemos que la ley es de observancia obligatoria a nivel nacional, salvo que indique lo contrario, se modifique o se derogue.

De estas definiciones se desprende que la inclusión como título de la sumilla "ámbito de aplicación" no es la más adecuada en la medida que no guarda correspondencia con el texto del artículo, motivo por el cual debe ser modificada por la de "Concepto de Mendicidad," o caso contrario modificar el texto del artículo indicando el ámbito de su aplicación.

Artículo $3^{\circ}$, segundo párrafo e incisos siguientes, prescribe que para el logro de los objetivos de la presente Ley, además de las acciones preventivas, adoptará las siguientes medidas:

a) Retiro de la calle y resguardo provisional de los niños y adolescentes quepractiquen la mendicidad.

b) Adopción de medidas necesarias para que el Juez Competente proceda a la notificación de los padres de aquellos que hayan sido ubicados practicando la mendicidad, a fin de que adopten medidas para evitar esta práctica, así como el seguimiento de estas recomendaciones.

c) Resguardo de los niños y adolescentes cuyos padres no adopten medidas para evitar que practiquen la mendicidad, previa autorización del Juez del Niño y del Adolescente ${ }^{8}$, así como el inicio de las acciones legales necesarias contra dichos padres.

d) Realización de exámenes a cargo de profesionales de la salud, a fin de prevenir la existencia de daño físico o moral derivado de la práctica de la mendicidad, así como la adopción del tratamiento correspondiente.

e) Desarrollar programas de apoyo y reinserción familiar y escolar para niñas, niños y adolescentes que practiquen la mendicidad.

7 Gómez de Silva, Guido (1998) Breve Diccionario Etimológico de la Lengua Española, Segunda edición 1998, sexta reimpresión 2009, p. 257, Editorial Fondo de Cultura Económica, México.

8 Texto Único Ordenado de la Ley Orgánica del Poder Judicial, Decreto Supremo No 017-93-JUS fecha de publicación, 3 de junio de 1993, en el Diario Oficial El Peruano, modifica el nombre de "Juez del Niño y del Adolescente" a "Juzgado de Familia en materia Tutelar," artículo $\mathrm{N}^{\circ} 53^{\circ}$. 
De la lectura de estos incisos se desprende que son disposiciones de carácter procedimental, propias de ser incluidos en el reglamento y no en la ley misma.

La redacción del primer párrafo del artículo $3^{\circ}$ señala que: Para erradicar la práctica de la mendicidad por parte de niños y adolescentes, es responsabilidad del MIMDES (hoy MIMP) "adoptar medidas inmediatas y ejecutar programas de prevención", y de ser el caso coordinará con el Ministerio Público, la Policía Nacional y el Poder Judicial..., para posteriormente regular, en el segundo párrafo del artículo $4^{\circ}$, que "los Comités desarrollaran las labores de prevención previstas en la presente Ley" y...; de esta redacción no queda claro si las palabras "ejecutar" $y$ "desarrollar" se utilizan como sinónimos, porque si así fuere se estarían duplicando funciones generando dificultades al momento de su aplicación. (ver anexo 01)

Punto pendiente a dilucidar, en la medida que aún, a ciencia cierta, no tengo información concreta de la conformación de los Comités a nivel Regional y Local; sin embargo, consultada que fue la Municipalidad Distrital de Miraflores, mediante solicitud formulada al Área de Participación Vecinal, Bienestar Social, de fecha 29-08-14, sobre la existencia del Comité de Participación Pública y Privada, respondió mediante documento signado con el número $2014^{\circ}$, informando y mostrando fotos sobre la actividad desplegada por la gestión del actual Alcalde - Sr. Muñoz - a favor de la niñez con otras autoridades, lo cual es loable y ejemplar, sin referirse, en extremo alguno de su comunicación, sobre la consulta formulada.

Con fecha 19-01-2005, se publica en el diario oficial de El Peruano, el D.S. 005-2005-MIMDES que aprueba el Reglamento de la Ley N$^{\circ} 28190$, el cual en su artículo $2^{\circ}$ desarrolla, ampliando su contenido, otro concepto sobre la mendicidad, distinto al desarrollado en la Ley, cabe preguntarnos si un reglamento puede modificar la Ley.

Un punto a criticar, por su relevancia, está referido al Título $V$ del Procedimiento, el cual convierte una intervención $\mathrm{u}$ operativo en un proceso lento y burocrático, en total discordancia con la parte infine del artículo $3^{\circ}$ que dice:

"Para el logro de los objetivos de la presente Ley, además de las acciones preventivas, adoptará las siguientes medidas: 
Y conel literal a) del mismo artículo que prescribe:

"Retiro de las calles y resguardo provisional de los niños y adolescentes que practiquen la mendicidad."

Este inciso, por su redacción, es de carácter imperativo, por lo tanto, debe cumplirse sin perjuicio de lo regulado por el reglamento de la Ley.

Es de indicar que en el inciso precitado se omite incluir a las niñas.

Como reseña histórica, atinente al caso, Isaac F. Montoro, en su libro titulado "Yo fui mendigo" ${ }^{9}$ narra sus experiencias como reportero de Expreso ocurrida en 1961, sumergiéndose en el mundo de la mendicidad limeña para proporcionar a sus lectores una versión exacta de la condición de mendigo ${ }^{10}$ El capítulo V narra el tema de "Los Niños Alquilados y el Mendigo Asiático", respecto de los niños alquilados, cuenta que vio bajar de un vehículo a una mujer acompañada de un niño, con la que entabló conversación y en la misma "se entera que el chico no era su hijo y que contaba con seis años de edad y que se lo alquilaban por cinco soles, que era hijo de su comadre que vive en la barriada $E l$ Agustino". Ella está abandonada como yo. Pero no puede quejarse porque llevan buena plata a su madre, "A la salida del cine el chofer vendrá a recogernos". Es padrastro del niño. Este relato, acaecido aproximadamente hace 54 años, nos muestra que la situación sobre la mendicidad no ha cambiado en el país. La pregunta es ¿por qué?

De lo desarrollado líneas arriba podemos extraer algunas conclusiones, tales como:

Es una realidad que parte de nuestra legislación, relacionada al tema de la niñez, procede del derecho occidental y que el texto básico para la protección de los derechos del niño, niñas y adolescentes parte de la Convención sobre los Derechos del Niño.

La mendicidad de niños, niñas y adolescentes se configura por la situación de necesidad, abandono y caridad pública, así como por la explotación a la que se encuentran sujetos por sus familiares como por terceros que los alquilan.

\footnotetext{
${ }^{9}$ Montoro, Isaac. (1978) Yo fui Mendigo. Promoción Editorial Inca S.A. tercera edición, p.39

$10_{\text {Tbíd., prólogo. }}$
} 
No se considera como actividad productiva cualquiera sea su condición.

No debemos negarles el derecho a su integridad moral, psíquica y física y a su libre desarrollo y bienestar,... la igualdad ante la ley ${ }^{11}$, consintiendo su discriminación, contraviniendo nuestras normas de carácter constitucional y demás leyes y violando el compromiso asumido por el Perú al ser parte de la Convención sobre los Derechos del Niño del 26-01-90

- Transcribo el artículo $2^{\circ}$, numeral $2^{\circ}$ de la Convención aludida, la cual manda que:

"Todos los Estados parte tomarán todas las medidas apropiadas para garantizar que el niño se vea protegido contra toda forma de discriminación o castigo por causa de la condición, las actividades, las opiniones expresadas o las creencias de sus padres, o sus tutores o de sus familiares."

Con la conducta anómica, de la normatividad vigente, tanto de las autoridades como del colectivo civil involucrado, se niega el proyecto de vida, de salud, educación, buen trato a su desarrollo personal, respeto a su condición de seres humanos de los niños, niñas y adolescentes, y, más bien, se les condena a seguir viviendo en un escenario que los daña física y psicológicamente, ocasionando, como secuela, un futuro incierto en sus vidas, con salud mental deteriorada, encaminándolos, en muchos casos, al mundo de la delincuencia, drogadicción y prostitución, entre otras actividades ilícitas y nocivas para la sociedad.

- La importancia de conocer cuál es la correlación existente entre el gasto social dedicado a la familia y la tasa de riesgo de pobreza infantil, por cuanto, en la medida en que se incremente el presupuesto económico de ayuda a ese sector, será una realidad que disminuya la pobreza y como consecuencia la presencia de los niños, niñas y adolescentes en la calle en estado de mendicidad, conclusión a la que arriban especialistas en economía, tema de constante debate en nuestro país que, de no ser resuelto acertadamente, pone en compromiso el destino de nuestra sociedad.

\footnotetext{
${ }^{11}$ Sar, Omar A. (2005) Constitución Política del Perí de 1993 con la jurisprudencia del Tribunal Constitucional. Ed. Nomos \& Tesis, $2^{\mathrm{a}}$. edición, 2005, pp. 21, 25.

12 Novak, Fabián y Salmón, Elizabeth. (2000) Las Obligaciones Internacionales del Perú en Materia de Derechos Humanos. Adoptada por el Perú el 20-11-89 (Res. A.G. 44/25) entrada en vigor el 02-09-90 y entra en vigor para el Perú el 04-10-90, Fondo editorial de Pontificia Universidad Católica del Perú, enero, p. 23.1
} 
Respecto a la sumilla del artículo $2^{\circ}$ de la Ley $\mathrm{N}^{\circ} 28190$, recomiendo la publicación de la norma modificatoria por la falta de coherencia entre la sumilla y el contenido del artículo por: "Concepto de Mendicidad"; o, en todo caso, si se trata efectivamente del ámbito de aplicación indicar que: "El ámbito de aplicación de la presente Ley está dirigida a todos los niños, niñas y adolescentes que se encuentren en estado de mendicidad o en situación de calle a nivel nacional".

- En relación a la ambigüedad de las palabras "ejecutar" y "desarrollar" referidas a las prevenciones que fija la Ley para el MIMDES (hoy MIMP) y para el Comité no define meridianamente cuál de ellos es el que debe actuar frente a las prevenciones, por consiguiente, soy de opinión que el citado Comité, por su jerarquía dispuesta en la Ley y dependencia a la que se encuentran sujetos a los Gobiernos Regionales y/o Locales, así como del propio MIMDES (hoy MIMP) deben, más que desarrollar, "colaborar y contribuir con diligencia en las actividades dirigidas a rescatar a los niños, niñas y adolescentes en estado de mendicidad y en situación de calle", por consiguiente, se debe redactar el dispositivo legal modificatorio en ese sentido.

\section{Noción de Infancia}

Los de mayor prudencia se atienen a lo que necesitan saber los hombres, sin tener en cuenta lo que pueden aprender los niños.

Buscan siempre al hombre en el niño, sin considerar lo que éste es antes de ser hombre.

Rousseau. ${ }^{13}$

El vocablo Infancia proviene del latín infantia; su primera acepción significa estado de niño. Los primeros tiempos de la humanidad. ${ }^{\mathbf{1 4}}$

\footnotetext{
13 Montero González, Soledad Martha, El Emilio: niño y educación. En la introducción de su artículo cita estas palabras de Juan Jacobo Rousseau en 1762 de su desarrollo filos6fico en el tratado pedagogico.

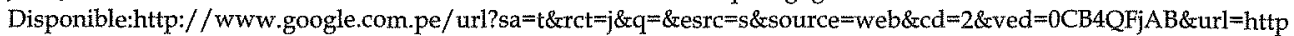
$\% 3 \mathrm{~A} \% 2 \mathrm{~F} \% 2 \mathrm{Fdialnet}$ unirioja.es\%2Fdescarga \%2Farticulo\%2F3324464.pdf\&ei=UkgjVPqoC4KTgwS84YGYBw\&us $\mathrm{g}=\mathrm{AFOjCNF2fIW8G1DCy5wpW4a}$ _qaxwFAHAWw , consultado el 20-09-14

14 Moliner, María. (2008) Diccionario de Uso del español, Edición Electrónica, Versión 3.0. 2008, preparado por la Editorial Gredos, Madrid, España.
} 
La Doctora en Derecho María de la Válgona, en su libro: "Padres sin derechos Hijos sin deberes, el Laberinto Jurídico de la Infancia"15 señala diferentes etapas de la infancia y que a continuación transcribo por su importancia:

En la introducción de su libro manifiesta que:

"[...] Hay que considerar niño, teniendo en cuenta la edad sí, pero distinguiendo como hace la psicología evolutiva, en primera infancia -hasta los 6-segunda hasta los 12 y adolescencia a los 18 , juventud hasta los 25 , con una tendencia mayoritaria a ir rebajando la edaden cadaetapa.[... $]^{\prime 16}$ infancia,"17

"Erasmo, Rebelais y Montaigne, serán los primeros en ocuparse de la

"Durante siglos, los niños no tuvieron derechos reconocidos, estaban bajo la patria potestad que se ejercía de acuerdo con las normas o costumbres establecidas, pero que solía ser absoluta y con frecuencia tiránica." ${ }^{18}$

"Cita que Rousseau en su obra Émile declara que - quien no pueda cumplir con los deberes de un padre no tiene derecho a convertirse en padre-." 19

"Refiere que, [...] en Inglaterra hasta 1815 no era delito robar un niño a no ser que estuviese vestido, en cuyo caso el delito se cometía respecto de la ropa" ${ }^{20}$

“Reseña que el siglo XX es el siglo de la infancia, señalando que: A finales del siglo XIX y sobre todo a principios del siglo XX, en 1910 se empieza a percibir las injusticias sufridas sobre todo por niños inmigrantes que trabajaban en molinos o en las minas y por los niños abandonados o criados y maltratados en orfanatos." 21

\footnotetext{
15 Válgoma, María de la. (2013) Padre sin derechos, hijos sin deberes, el laberinto jurídico de la infancia. Ed. Ariel, $1^{\text {a. }}$ edición: febrero, España.

${ }^{16}$ Ibíd., p. 18 .

${ }^{17}$ Ibíd.,p. 48 .

18 Ibíd., pág. 49.

19 Ibíd., pág. 49.

20 Ibíd., pág. 52.

21 Ibíd., pág. 53.
} 
En la parte final del capítulo $2^{\circ}$. la autora concluye señalando que:

"La consideración no solo social sino también jurídica del menor ha pasado de la noche al día, de la noche más absoluta pasividad a la claridad de ser sujeto y como tal con plenitud de derechos. En pocos años se ha recorrido un larguísimo camino, llegándose a la culminación del reconocimiento jurídico de los menores como personas capaces." 22

De otro lado, es de señalar que la cultura occidental, en el devenir de la historia, fija como patrón social para los niños, niñas y adolescentes que:

"Deben ir a la escuela, deben jugar, obedecer las órdenes de sus padres y adultos, respetar las normas, los usos y costumbres; realidad social que solo se da en sectores minoritarios de nuestro país, sobre todo en las áreas urbanas, como consecuencia de muchos factores, por ejemplo: culturales, étnicos, geográficos, económicos, laborales, etc."

Factores que, entre otros más, han permitido que países como el nuestro asuman, como ideal, ese modelo de educación para nuestros niños, niñas y adolescente.

Pareciera que nuestras autoridades, al desarrollar los programas educativos o de rescate, a favor de este grupo etario, no tuvieran en cuenta la realidad pluricultural de nuestro país, en el que convivimos diferentes tradiciones culturales, desarrolladas por varias etnias o grupos poblacionales y en diferentes zonas geográficas.

Desde la perspectiva psicológica ${ }^{23}$, un sector de los NNA sometidos a la violencia por sus familiares va desarrollando la tolerancia en el ámbito familiar, social o escolar; tiene la impresión equivocada de que son responsables por lo que les sucede en sus hogares, visualizando en esta conducta una tendencia a que se trasmita de generación en generación.

Por estas razones y otros más, muchas familias peruanas al no contar, por falta de trabajo, con los medios económicos necesarios para lograr la educación de sus hijos, estos, terminan realizando labores inapropiadas para

${ }^{22}$ Ibíd., pág. 55.

23 Lizana Zamudio, Raúl. (2012) A mí también me duele, Niños y Niñas víctimas de la violencia de género en la pareja. Editorial Gedisa, $1^{\natural}$ edición. Barcelona. España. Resumen extraído pp. 145 a 147. 
su edad, trabajando en las calles, explotados en las canteras, minas o mendigando para sobrevivir.

Otro factor influyente, para la presencia en las calles de muchos niños, niñas y adolescentes de nuestro país, a pesar de la normatividad y programas existentes, está relacionado con las mafias existentes, que en complicidad con familiares o extraños, los utilizan y/o alquilan para diferentes actividades, exponiéndolos a situaciones de riesgo para su integridad física como moral, el único objetivo, para estas organizaciones delictivas, es obtener ingresos económicos en perjuicio de los menores, afectando los derechos fundamentales de este grupo etario que, por mandato imperativo de nuestras normas de carácter nacional e internacional, debemos proteger.

De lo ya mencionado, se colige que en nuestro país un sector de la infancia favorecida goza de una buena educación, salud y derechos, y la otra parte de la población infantil, la excluida, la marginada, vive explotada en diferentes actividades: minería, construcción, agricultura, venta ambulatoria, como domésticos, también como sicarios a tan corta edad, al tráfico y consumo de drogas, prostitución infantil, entre otras actividades dañinas más.

Estas son las lamentables y grandes diferencias que deben ser eliminadas de nuestro país para construir una gran nación. No olvidemos que el Estado Peruano es garante de los derechos del universo social infantil peruano así como de los infantes extranjeros afincados en nuestro territorio.

André Comte-Sponville ${ }^{24}$ en su libro "Pequeño tratado de las grandes virtudes", cita un párrafo de la obra Ética a Nicómaco escrito por Aristóteles que dice:

"La justicia se articula por entero en ese doble respeto de a la igualdad, en el Estado, y a la igualdad, entre individuos: <<Lo justo es lo que se conforma a la ley y lo que respeta la igualdad, y lo injusto es lo que es contrario a la ley lo que no respeta la igualdad $>>$

\footnotetext{
${ }^{24}$ Comte-Sponville, André. (2003) Pequeño tratado de las grandes virtudes, $1^{\text {a }}$ edición en esta presentación, octubre, Editorial Paidos, Madrid, España.
} 


\section{Normatividad Vigente}

El marco normativo, vigente en nuestro país, que regula los casos de protección a los menores de edad que se encuentran en estado de mendicidad, es el siguiente:

- Constitución Política del Perú de 1993

- Declaración Universal de los Derechos Humanos. Art. $1^{\circ}$

- Convención Americana sobre Derechos Humanos. Art. $5^{\circ}$, numeral 1)

- Convención sobre los Derechos del Niño. Arts. $3^{\circ}, 4^{\circ}, 19^{\circ}$ y $32^{\circ}$

- Código de los Niños y Adolescentes aprobado por Ley 27337. Art. $40^{\circ}$

- Código Penal. Art. $128^{\circ}$

- Ley Orgánica Regional. Art.60, inc.h)

- Ley Orgánica de Municipalidades. Art. $84^{\circ}$ inc. 1, literal 1.2, 1.3; Inc. 2, literal 2.4, 2.8; Inc. $3^{\circ}$, literal $3.2 ;$ Inc. $5^{\circ}$, literal 5.4

- Ley Orgánica de la Policía Nacional del Perú, Ley 27238. Art. $7^{\circ}$ inc. 4

- Reglamento de la Ley Orgánica de la PNP. D.S. Nº08-2000-IN. Art. $9^{\circ}$, inc. 9.5

- Ley que protege a los menores de edad de la Mendicidad, Ley 28190

- Reglamento de la Ley 28190 D.S. 001-05-MIMDES.

- D.S. 003-2005-MIMDES- Reglamento de las Funciones asignadas al MIMDES. Arts. $7^{\circ}, 8^{\circ}$ y $9^{\circ}$

- D.S. 027-2007-PCM. Art. $6^{\circ}$ inc. 6, literal 6.4, 6.56.6; art. 8, inc. 8.3

- D.S. 003-2010-MIMDES. Aprueban relación de trabajos peligrosos y actividades peligrosas o nocivas para la salud integral y la moral de los y las adolescentes.

- D.S. 001-2012-MIMP. Plan Nacional de Acción por la Infancia y la Adolescencia

- D.S. 005-2012-MIMP. Crea el Programa Yachay.

- D. LEG. 1098. Ley de Organización y funciones del Ministerio de la Mujer Poblaciones Vulnerables - MIMP.

\section{Referencias}

- Bhattacharjea, Suman. (1999) Infancia y Política Social. Ed. Fondo de las Naciones Unidas para la Infancia. (UNICEF). México

- Cabanellas, Guillermo. (1979) Diccionario Enciclopédico de Derecho Usual. Ed. Heliasta, Buenos Aires.

- Chebez, Víctor. (2009) Chicos que Trabajan, la injusticia cotidiana. Ed. Capital Intelectual. Barcelona. 
- Comte-Sponville, André. (2013) Pequeño tratado de las grandes virtudes. Ed. Paidos Madrid.

- Diccionario de la Real Academia Española DRAE, (2001) Versión Electrónica. Disponible en:http://wwwrae.es. consultado el 20-09-2014.

- Gómez de Silva, Guido. (1998) Breve Diccionario Etimológico de la Lengua Española. Ed. Abridged. Mexico.

- Lizana Zamudio, Raúl. (2012) A mí también me duele, Niños y Niñas víctimas de la violencia de género en la pareja. Ed. Gedisa, S.A. Barcelona.

- Moliner, María. (2008) Diccionario de Uso del español, Edición Electrónica, Versión 3.0 Ed. Grados. Madrid.

- Montoro, Isaac. (1978) Yo fui Mendigo. Ed. PEISA. Lima

- Montero González, Soledad Martha. (2009) El Emilio: niño y educación. En: Magistro Revista de la Maestría en Educación de la Vicerrectoría de la Universidad Abierta ya Distancia - Universidad Santo Tomas ISSN: 2011-8643 Bogotá disponible en Internet:http://revista.usta.edu.co/index.php/ magistro/article/view/610. Consultado el 20-09-2014.

- Novak, Fabián y Salmón, Elizabeth. (1978) Las Obligaciones Internacionales del Perú en Materia de Derechos Humanos. Ed. Fondo Editorial PUCP. Lima.

- Sar, Omar A. (2005) Constitución Política del Perú de 1993 con la jurisprudencia, artículo por artículo del Tribunal Constitucional. Ed. Normas \&Tesis Editorial Lima.

- Texto Único Ordenado De La Ley Orgánica Del Poder Judicial, Decreto Supremo No017-93-JUS.

- Umaña Luna, Eduardo, (1991) El Menor de edad. Estructura Legal y Coyuntura Social. Ed. Corporación Colectivo de Abogados, Universidad Nacional de Colombia. Facultad de Derecho. Santa Fe de Bogotá.

- Válgoma, María de la. (2013) Padre sin derechos, hijos sin deberes, el laberinto jurídico de la infancia. Ed. Ariel. Buenos Aires. 
(Anexo 1)

FLUJOGRAMA COORDINACIÓN DEL MIMP CON OTRAS INSTITUCIONES

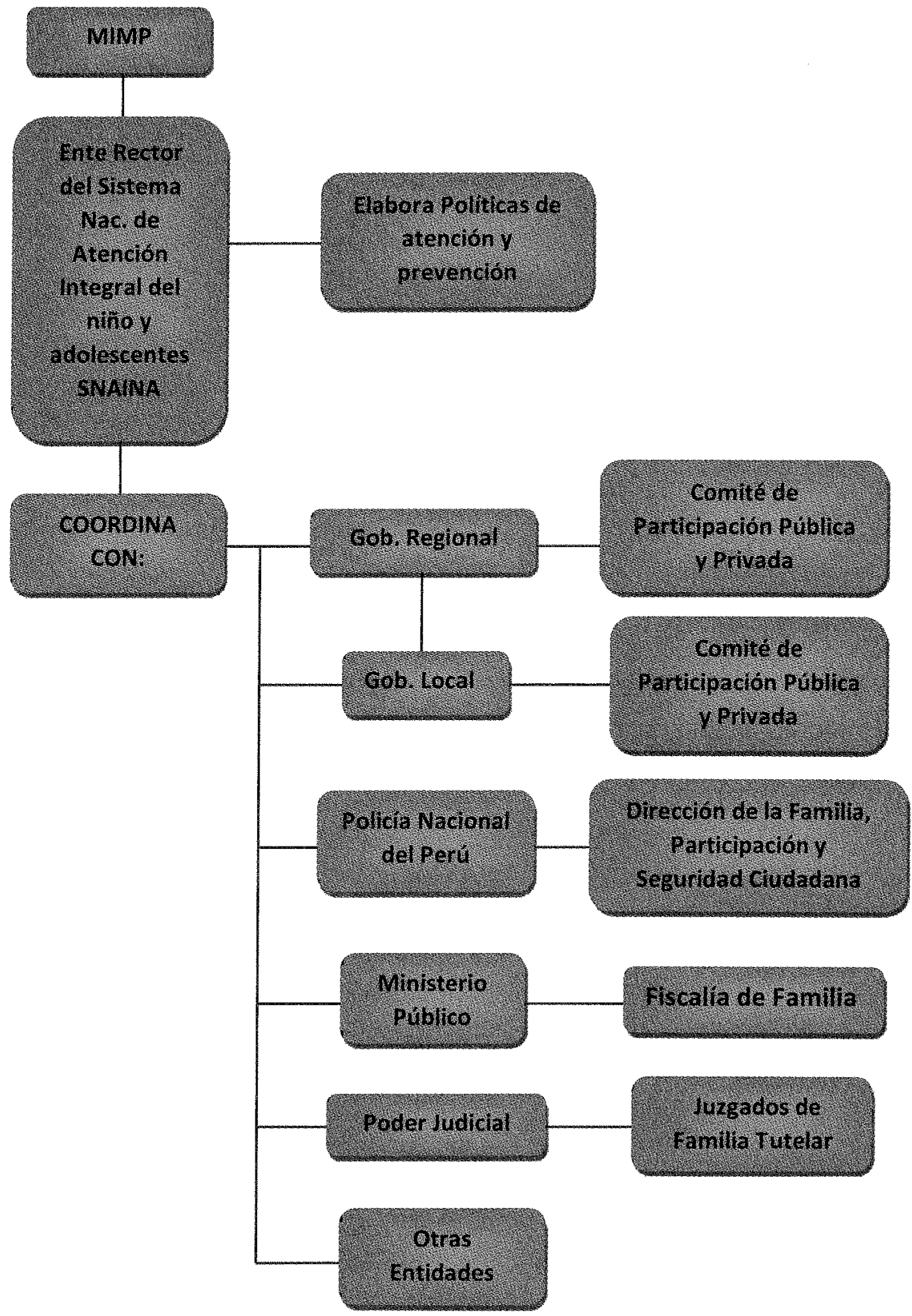




\section{(Anexo 2)}

FLUJOGRAMA DEL PROCEDIMIENTO

\section{Según lo determinado por el D.S. 001-2005-MIMDES}
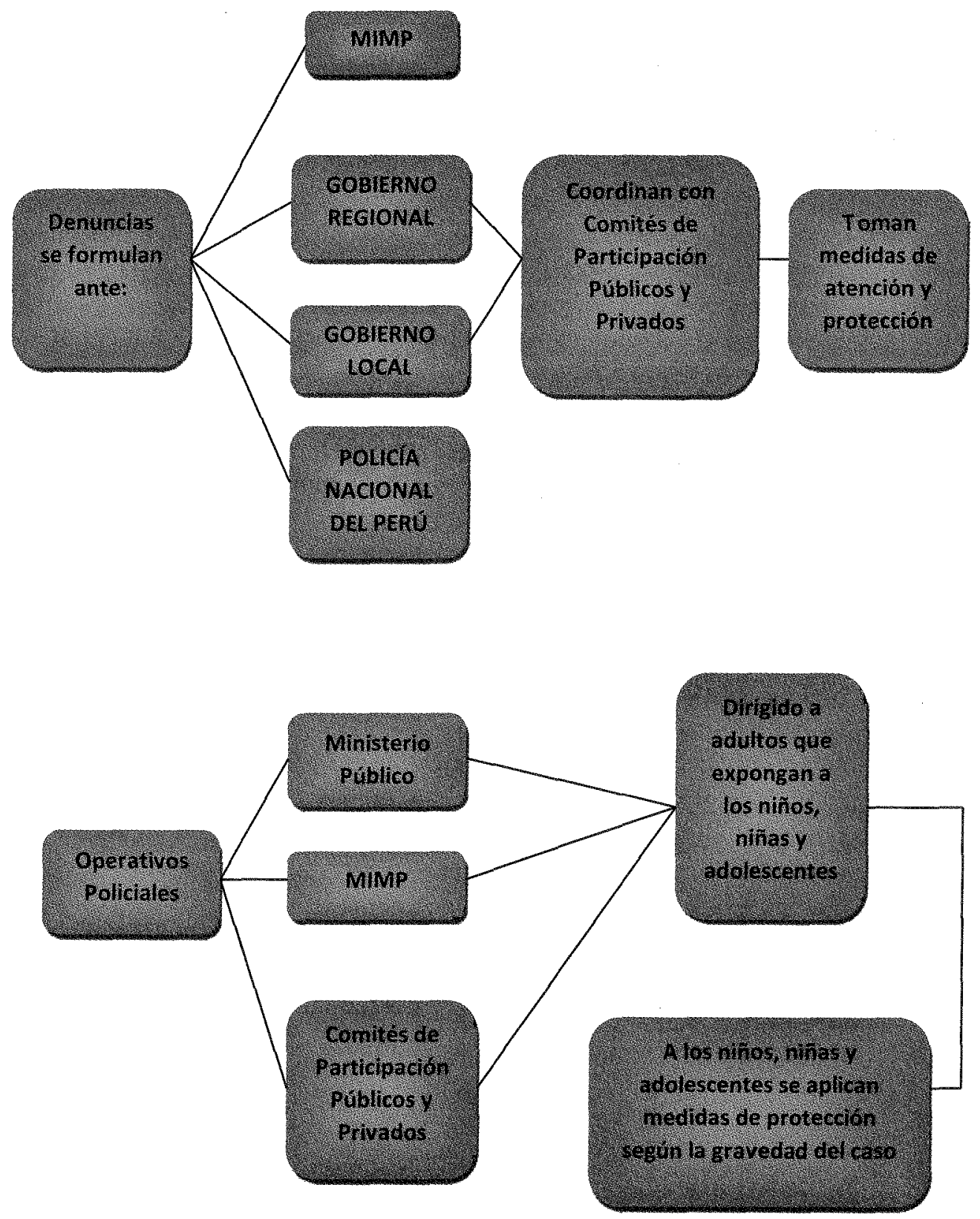
